\title{
Using History of Mathematics to Teach Volume Formula of Frustum Pyramids: Dissection Method
}

\author{
Suphi Onder Butuner
}

Department of Elementary Mathematics Education, Bozok University, Turkey

Copyright $(\mathcal{C} 2015$ by authors, all rights reserved. Authors agree that this article remains permanently open access under the terms of the Creative Commons Attribution License 4.0 International License

\begin{abstract}
Within recent years, history of mathematics (HoM) has become an increasingly popular topic. Studies have shown that student reactions to it depend on the ways they use history of mathematics. The present action research study aimed to make students deduce volume rules of frustum pyramids using the dissection method. Participants were 24 grade eight students from Trabzon. Observations, informal interviews and feedback forms were used as data collection tools. Worksheets were distributed to students and the research was conducted in 3 class hours. Student views on the activities were obtained through a written feedback form consisting of 4 questions. During the study, most students could assemble the parts forming frustum pyramids and find out volume rules of frustum square pyramids and frustum rectangular pyramids calculating the volumes of the geometric shapes obtained through that assembly. Several students had difficulties in recognizing geometric shapes as well as completing the calculations. The findings revealed that, prior to the study, most students were not able to complete similar activities and the mathematics course was taught in a teacher-centered way. Students found the activities interesting as well as instructing.
\end{abstract}

Keywords History of Mathematics, Dissection Method, Pyramid, Volume, Action Research

\section{Introduction}

Within recent years, history of mathematics (HoM) has become an increasingly popular topic. Previous studies have shown that student reactions to it are determined by how they use the history of mathematics. Therefore, before using historical content in classes, the aim and ways of using such content should be questioned. When researchers discuss their reasons for using history of mathematics in the classroom, they mostly state that history of mathematics will reduce student anxiety about mathematics, increase their motivation and attitudes towards learning, help them learn the subjects and concepts and reveal the multicultural, developing and dynamic structure of mathematics $[1,2,3,4,5,6,7]$. It is stressed that history of mathematics will enrich the repertoire of teachers and develop their pedagogical content knowledge [7, 8]. Jankvist [5] (2009) explains the use of history of mathematics both as a tool and as a goal. History-as-a-tool arguments are mainly concerned with learning of the inner issues of mathematics (mathematical concepts, theories, methods, formulas), whereas history-as-a-goal arguments are concerned with the use of history as a self-contained goal. From the history-as-a-goal point of view, knowing about the history of mathematics is not a primary tool for learning mathematics better. In using history as a goal, the learning of developmental and evolutionary aspects of mathematics either serves as a goal in itself or serves to illustrate other historical aspects of the discipline.

Jankvist [5] (2009) suggested three different approaches for the use of HoM in classrooms: "illumination", "modules" and "history-based" approaches. Within the illumination approach, the current curriculum is not changed but historical content is included. However, this can occur at different levels. Inclusion at a lower level may for instance include use of historical snippets, as mentioned by Tzanakis and Arcavi [7] (2002). The names of mathematicians, the periods they lived in, their studies, a historical film, life stories, renowned problems, anecdotes and copies of historical studies may all be regarded as historical snippets [7]. Swetz [9] (1997), Fried [3] (2001), Baki and Bütüner [10] (2013) argued that teacher emphasis on life stories of mathematicians, their studies and contributions to mathematics would barely make students move beyond the role of listener in the learning process. Jankvist [5] (2009) explained his modules approach as having course units including historical content. The historical based approach, on the other hand, includes units directly inspired by or based on the development and history of mathematics. Unlike the modules approach, the historical approach does not deal with the study of the history of mathematics in a direct manner, but rather in an indirect fashion. Here, the historical development is not necessarily discussed explicitly. When explaining the development of number sets, the developmental sequence should be followed starting from 
natural numbers.

The use of HoM in learning environments was mentioned by Gulikers and Blom [4] (2001) under the title of "general integration". The first use explained here involves providing historical knowledge about a certain period or a historical matter, or teaching a concept together with historical content in order to introduce the method. Gulikers and Blom pointed out that secondary resources might be used in order to give information about a subject or a concept. They explained the second use as teaching a concept or method together with historical content, and such as utilizing problems taken from original sources on mathematics. According to the researchers, studying primary sources enable students to discuss alternative solutions [4]. The International Commission on Mathematical Instruction (ICMI) provided special methods and examples as well as general approaches towards the use of HoM. Short historical passages, projects based on historical texts, primary sources, worksheets, historical packages, mistakes, alternative concepts, historical problems, mechanical tools, experimental mathematics activities, games, movies and other visual elements, trips to historical sites and the Internet were given as examples of using HoM [7].

Fried [3] (2001) mentioned two strategies about the use of HoM. The first, the addition strategy, includes activities such as using historical anecdotes, brief stories from the lives of mathematicians, historical problems or showing pictures of mathematicians. Through this approach, the current curriculum is not changed but its scope is extended. The other approach is the adaptation strategy. In this one, the teaching process is adapted to a historical schema, as in the adaptation of Katz and Napier's logarithms to contemporary classes. Fried stated that the implementation of both of these may result in specific problems such as trivializing history (whig approach) by misrepresenting time and date. In order to cope with these challenges, radical adaptation or radical accommodation strategies were recommended. Through radical adaptation, students learn mathematics studying primary sources with information both on mathematics and its history. Nooney [11] (2002) expressed that students will follow HoM content which is parallel to and in accordance with the mathematics course content through radical addition or radical accommodation strategies. Barnett, Lodder and Pengelley [12] (2014) used HoM in their studies through the reading of original historical sources. They suggested that this approach may prevent the problem of trivializing history (whig approach).

Fried [3] (2001) argued that mathematics educators should normally use historical content in two ways. The first is to include historical content but devalue history in order to teach modern mathematics, while the other is to include realistic historical content and risk wasting time due to irrelevant topics [3]. Another challenge in using HoM is the fact that students dissociate historical content from modern mathematics, which leads to confusion, believing that HoM is unnecessary, and loss of interest in mathematics [7, 13]. For this reason, it is important for teachers to have the required knowledge and experience of using history of mathematics. Teachers equipped with necessary knowledge and experience may keep students' attention through including appropriate historical content in their classes. Ho [14] (2008) and Panasuk and Horton [15] (2012) determined that teachers' lack of knowledge and experience is one of the greatest challenges before using history of mathematics in classes. Fried [3] (2001) gave the example of "geometrical algebra" and tried to explain that the way mathematics educators use HoM while teaching modern mathematics and modern mathematical techniques is different from that of mathematics historians. $x^{2}+6 x$ statement was explained by giving the example that the area of a square whose side length is $\mathrm{x}$ is equal to the area of a rectangle whose side lengths are 6 and $\mathrm{x}$. Girolamo Cardano included such geometric discussions in his book Ars Magna in order to justify his algebraic techniques. These facts are compulsory to build a good knowledge of history. However, the aim here is to benefit from the technique of completing the square in order to teach students the subject rather than history.

Studies conducted in this field have shown that the reactions of students are based on the ways they use the history of mathematics. Glaubitz [16] (2007) included historical content in his study using primary sources. The students included in the experimental group examined al-Khwarizmi's book entitled "Al Kitab Fi Hisab Al Cabr wal Muqabalah" and studied the "technique of completing the square". They examined verbal and geometrical solutions of al-Khwarizmi and discussed his solutions in small groups. Afterwards, they tried to solve second degree equations using al-Khwarizmi's way. This gave them an opportunity to discuss the advantages and disadvantages of al-Khwarizmi's solutions and compare them to modern ones. The study led to a discussion about negative numbers, too. As for the students in the control group, they spent six class hours doing regular exercises on second degree equations. At the end of the process, experimental students were not only more successful than control students but they had also enjoyed the practices more.

Nataraj and Thomas [17] (2009) used historical content in their study in order to make students comprehend the structure of the decimal number system and the concept of "decimals". During the first stage of the study, students were asked to create number systems by themselves. After that, a pre-test was given in order to determine students' prior knowledge about the decimal number system. Following the pre-test, students studied the characteristics of ancient number systems and converted them into modern ones. Finally, students showed large numbers with sticks and bundles based on the development stages of number systems. This was followed by a post-test aiming to determine students' development compared to their pre-test scores. After these practices, it was revealed that except for one, all students were able to generalize and comprehend the general structure of the decimal system and the decimal number system. Except for one, all students could write examples of large numbers in different ways. Moreover, except for two 
students, all thought that using sticks to show numbers entertaining and easy. Nataraj and Thomas used historical content in order make students better grasp the decimal system and the concept of "decimals" rather than converting the numbers used in Ancient Egypt and Babylon into modern ones or vice versa.

Bütüner [18] (2014) enriched $8^{\text {th }}$ grade mathematics classes with historical content in his study. The results showed that the students enjoyed the process as the activities required use of concrete learning objects, included paper cutting, painting and glueing activities, were not disassociated from modern mathematics, played along with the goals and objectives of the mathematics curriculum, and used groupwork. Although a good number of students expressed positive opinions on the activities, each had encountered challenging and complicated activities as well as those they deemed unnecessary considering the upcoming placement test. The activity of extraction technique in Babylon was a challenging and complicated one for the students. They expressed that the modern technique was more practical and useful. As a result, it may be concluded that not all historical content can be expected to help students develop positive attitudes towards mathematics. The purpose of using historical content, whether it is disassociated from modern mathematics or not, and the time spent on historical content within this context affect student views about the integration of historical content into classes.

The studies of Dickey [19] (2001), Tözluyurt [20] (2008), Kaye [21] (2008), Özdemir and Y1ldı [22] (2015) showed that students were ill-disposed towards historical content and encountered difficulties. Dickey [19] (2001) examined the impact of using HoM on $8^{\text {th }}$ grade students' learning and attitudes. The number systems of Ancient Egypt, Babylon and Islamic Cultures, multiplication, division and fractions in Ancient Egypt and multiplication and division in Indian culture were used as the historical content. The study concluded that students found all of the activities boring except for the gelosia method of multiplication. Tözluyurt examined the opinions of high school seniors on historical content oriented activities [20] (2008). The results revealed that all students had found fractions in Ancient Egypt difficult. During the Ancient Egyptian hieroglyph activity, some students lost their interest as they were anxious about the upcoming student selection examination, while some others found drawing hieroglyphs difficult. Of all the activities, Treviso arithmetic-multiplication was the students' most favorite activity. Kaye [21] (2008) conducted a videoconference for teachers and ten-year-old students from four different schools about mathematics of Babylon in his study. All students had difficulties in writing Babylon numbers. A similar result was obtained in the study conducted by Özdemir and Yıldı [22] (2015). The reason for the failure of using historical content may be attributed to the fact that the activities used were not associated with the objectives in the curriculum.

Comprehension of the process is highly important in teaching mathematics. The curriculum views learning mathematics as an active process, emphasizes students' active role in learning, supports the use of concrete models and expects students to be agents of their own learning. Students should be supported to make inferences from concrete experiences and to use abstracting. It should not be inferred from these that using life stories of erudite mathematicians, their studies and certain important anecdotes is a futile effort. However, it is true that including historical content not directly associated with the objectives of the curriculum causes students to develop a negative attitude towards the use of history of mathematics.

\section{Historical Content in Mathematics Textbooks in Turkey}

It is emphasized in the Turkish secondary school mathematics curriculum that history of mathematics may be used through life stories of erudite mathematicians, their studies, contributions to the field of mathematics and historical anecdotes to enable students to understand the multicultural, manmade structure of mathematics. It is stated that in this way students can maintain a positive attitude towards mathematics and learning it. In conclusion, positive student attitudes towards mathematics and its learning are associated with their perception of the multicultural, manmade structure of mathematics within the curriculum. Examples of historical content in the $6^{\text {th }}, 7^{\text {th }}$ and $8^{\text {th }}$ grade mathematics textbooks in Turkey are given below [23, 24, 25]. 
"Sayıların babası" olarak bilinen Pythagoras (Pisagor), M.Ö. 580-M.Ö. 500 tarihleri arasında yaşamıştır. En iyi bilinen teoremi, adıyla anılan Pisagor Teoremi'dir. Doğum yeri olan Sisam Adası'ndan Güney İtalya'ya göç ederek burada bir okul kurmuştur. Pisagor müzik ile de uğraşmış, telin kısalmasıyla çıkardığı sesin inceldiğini keşfetmiştir.

Yaklașık 2500 yıl önce yaşamasına rağmen çalışmaları günümüzde hâlâ kullanılan Pisagor gibi bildiğiniz başka matematikçiler var mı?

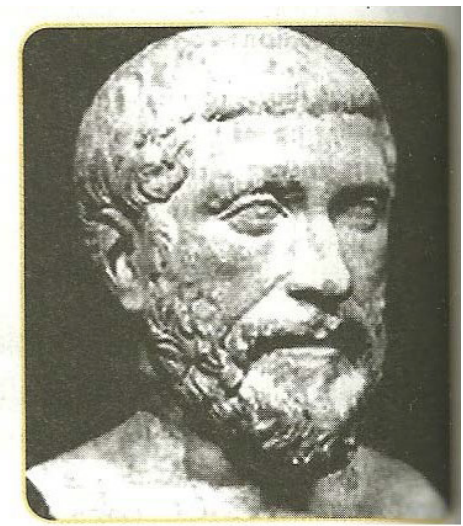

Example 1. A brief summary of Pythagoras's life and his picture ( $8^{\text {th }}$ grade textbook, page 80 )

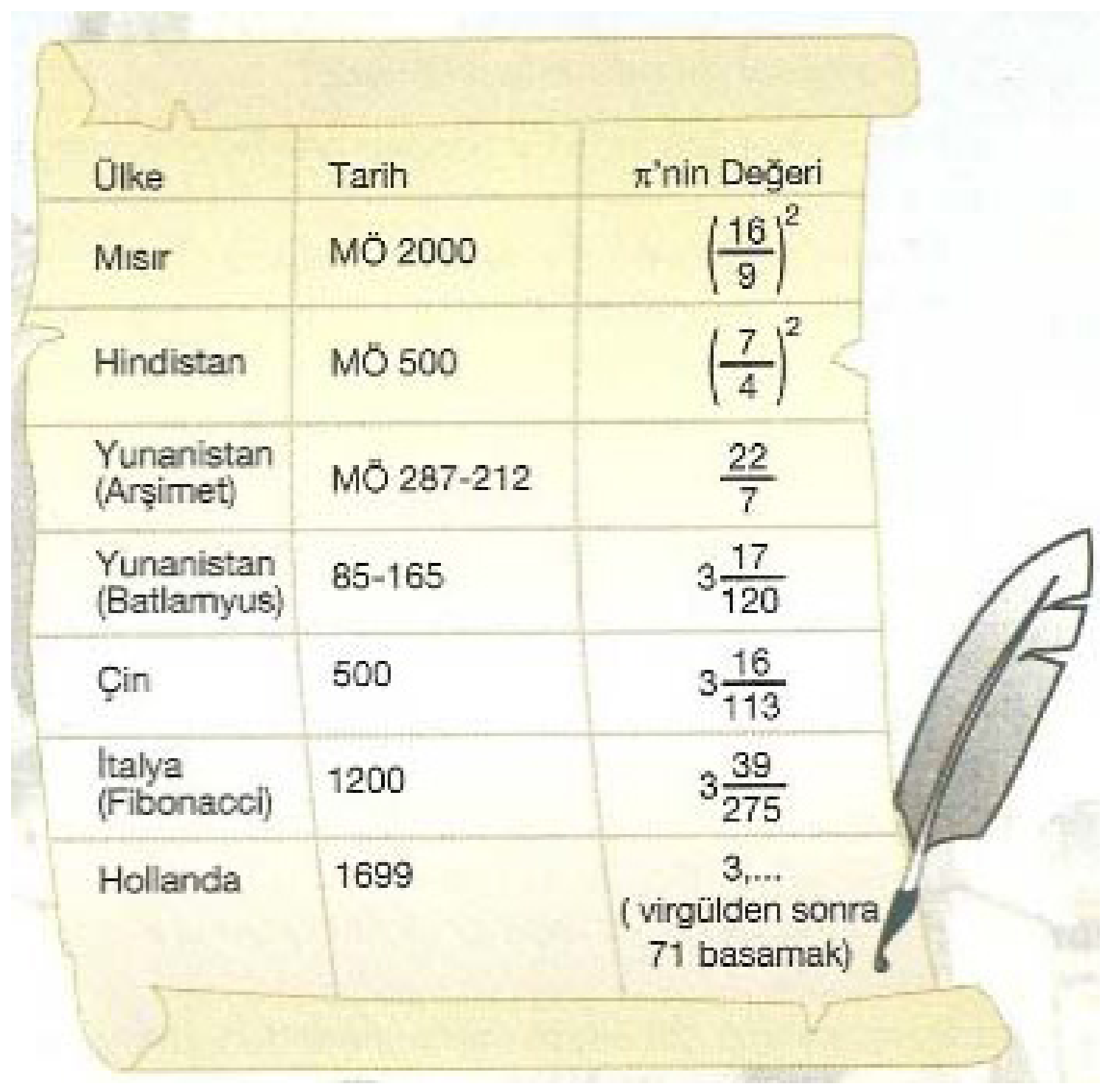




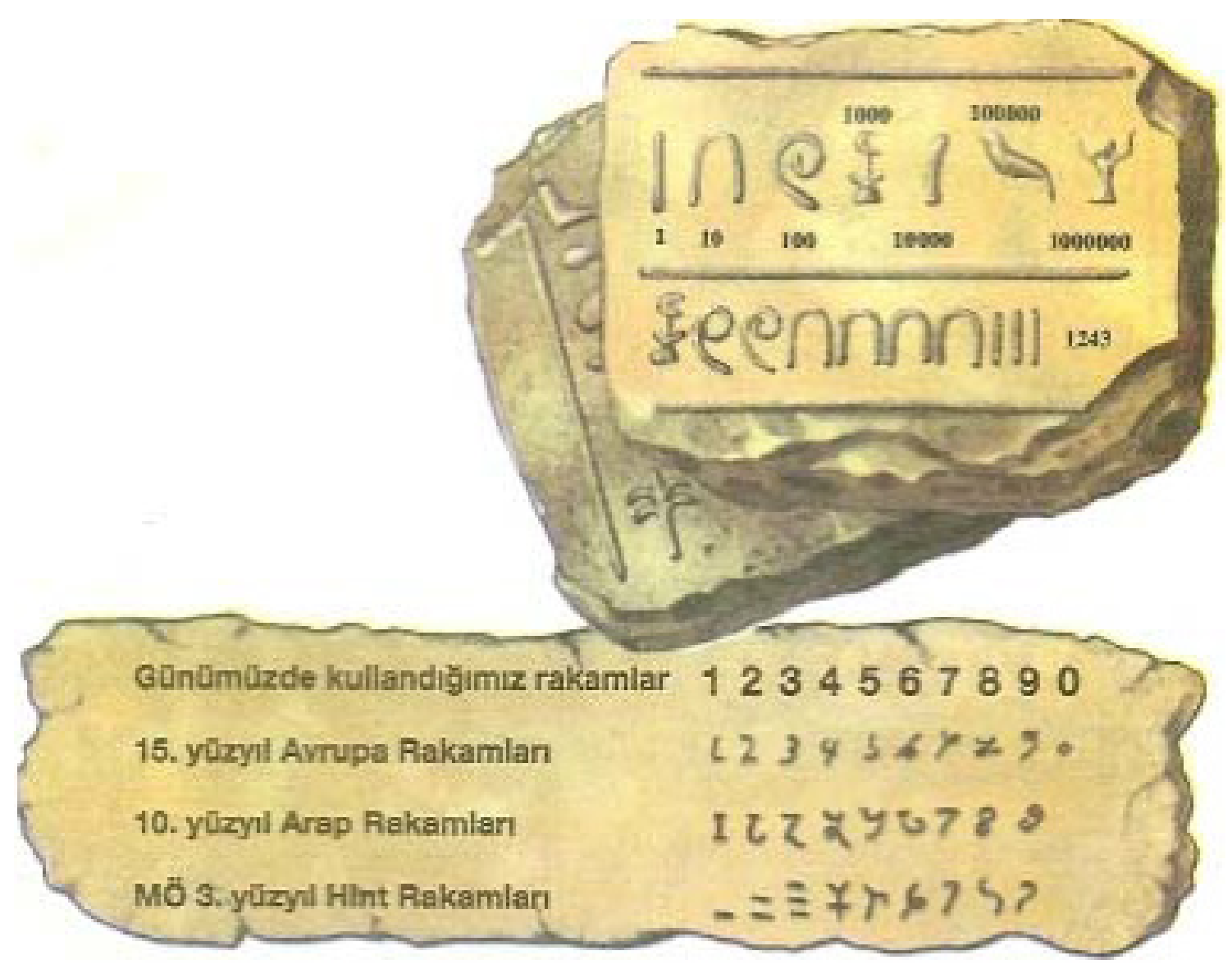

Example 2. Different values of the Pi number in various cultures, numbers in different cultures $\left(7^{\text {th }}\right.$ grade - page $211,6^{\text {th }}$ grade - page 108$)$

Topics in Turkish secondary school mathematics textbooks start with short historical passages (life stories of mathematicians, their pictures, ancient numbers, books, etc.) that do not include students in the process as active agents [10]. The curriculum brings a historical perspective into the classroom; however, students remain mere listeners as teachers talk about life stories of mathematicians, their works and contributions to mathematics [3, 9]. Comprehending the process is highly important for teaching mathematics. The curriculum handles the matter of learning mathematics as an active process, emphasizes that it is important for students to be active participants, supports the use of concrete models and expects students to be actors in their own learning processes. Students should be supported in the interpretation of concrete experiences and abstracting [26]. They should work out the source of a mathematical formula, rather than just hear it from their teachers. Only by generating formulas can they learn conceptual knowledge and become participants of a true mathematical process. Students who learn the source of formulas do not regard them as mysterious or try to memorize them. Taking formulas from a book in a haphazard way does not provide any of the opportunities listed above [27].

In light of the facts stated above, students should be encouraged to interpret new information linked to their former knowledge, deduce the rules and formulas of mathematics by themselves, and become active participants in the process with the help of content in line with the objectives of the curriculum. The instructional process should therefore include activities that enable students to see mathematics as a network of interdependent concepts and thoughts which they may interpret by themselves rather than memorize. The study was conducted in a classroom where the researcher was a counselor. The aim was to make students produce volume formula of frustum pyramids with the help of the "dissection method" from history [28, p.139, 140]. It was expected that such an activity would comprise appropriate historical content in line with the course objectives, make students active participants in the process, and help them construct new knowledge on their existing one. For this purpose, worksheets were used in the teaching environment and both student and researcher teacher views were obtained.

\section{Methodology}

Action research was chosen as the method of this study as the researcher also worked as a mathematics teacher during the study. Action research is a procedure that may be carried out by teachers in their own classes. Through action research, teachers may improve the quality and efficiency of their own teaching. A well-organized action research study may contribute to the professional development and performance of a teacher [29]. The starting point of an action research 
may be the potential efficiency of a novel teaching method, strategy or practice, as well as a problem encountered in class or an interesting educational issue that the teacher is curious about [30]. This study was conducted with students who had not before encountered historical content in class, and the efficiency of the activities was investigated. As historical content, Turkish secondary school mathematics curriculum and textbooks include the life stories of erudite mathematicians, anecdotes, ancient number systems, etc. This encourages students to be passive listeners. Despite the rich content that history of mathematics may provide, textbooks do not include concrete models, proofs or problem-solving methods used by erudite mathematicians in history. Therefore, the activities used in this study were prepared in order to help students figure out mathematical rules by themselves using methods taken from history. The study followed the fours stages of action research suggested also by Mertler [31] (2006): "Planning", "Acting", "Developing" and "Reflecting".

\section{Participants}

The research was conducted with a total of $248^{\text {th }}$ grade students in Trabzon, Turkey. Of these, 13 were male and 11 female. Students were named S1, S2, S3 ... S24 for the study. Heterogeneous groups were formed considering students' previous mathematics grades. Once the groups were formed, they were asked to choose speakers. The representatives of the groups were S6, S18, S10 and S2, respectively. Interviews were made with these representatives during the activities.

\section{Data Collection Tools}

Data collection tools used in the study are explained below:
Prepared by the researcher, worksheets were reviewed by two expert academics in the field. A trial was conducted on 27 students after the required corrections were made. Where there were ambiguous terms, clarifications were made and the worksheets were made ready for the study. In order to draw students' interests, several questions were used in the worksheets: What would you say if someone told you that a mathematical rule was decided around $3000 \mathrm{BC}$ with a solution different than the one we use today? Would you believe that this was possible 5000 years ago? Ask these questions to yourself once again after doing the exercises below.

In this study, students were divided into heterogeneous groups. The groups were formed according to student grades from the previous year in $7^{\text {th }}$ grade. Students tried to find the volume rules of frustum pyramids and frustum rectangular pyramids using the dissection method and concrete models. As the aim of this study was to contribute to cognitive and affective learning of students, history of mathematics was used as a tool in it. The activities conducted aimed to help students understand that mathematics is not a field based only on rules and formulas, but it has emerged in response to daily needs, been a topic of interest throughout history, and been practiced in different ways. In addition to this, it was expected that concrete models which require students to find the rules by themselves would arouse their interest and facilitate the learning process. The parts of frustum square pyramids, geometric models to be formed by completing these parts, and the completed frustum square pyramid model are given in Figures 1, 2 and 3, respectively. The materials used in the activity and the worksheets were prepared by the researcher teacher and distributed one for each group.

\section{Worksheets}

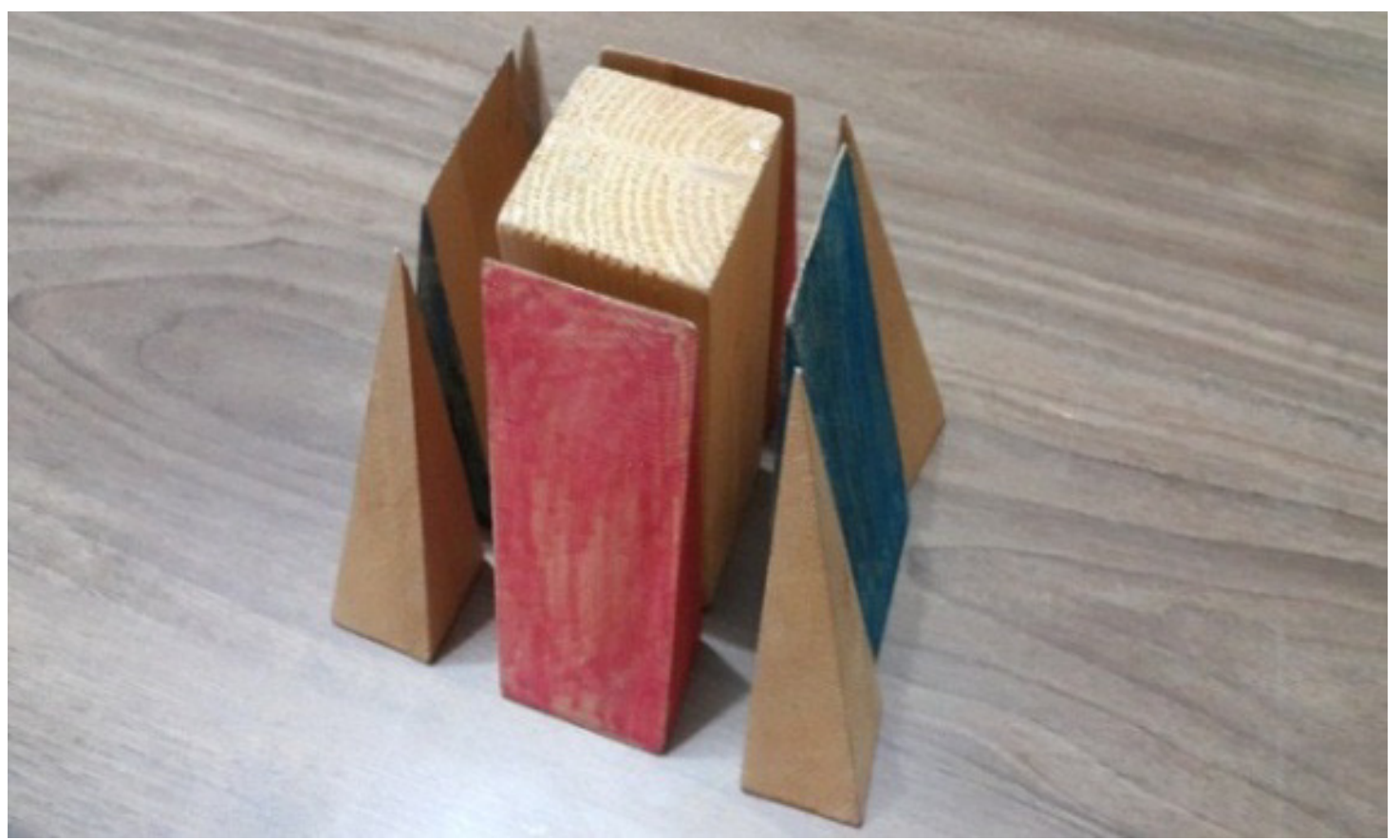

Figure 1. Parts of the Frustum Square Pyramid used in the Study 


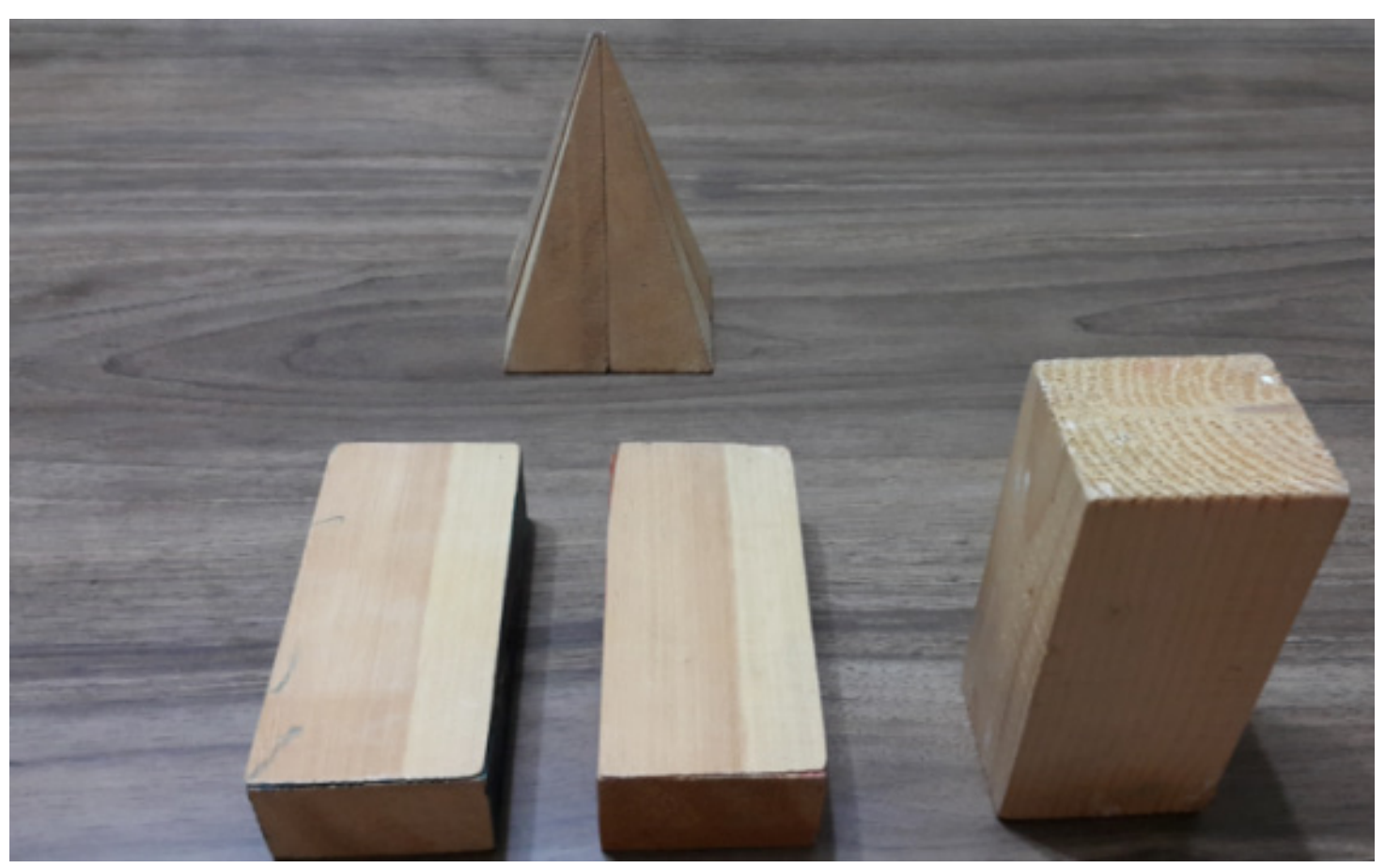

Figure 2. Forming Geometric Models by Completing the Parts of Frustum Square Pyramid

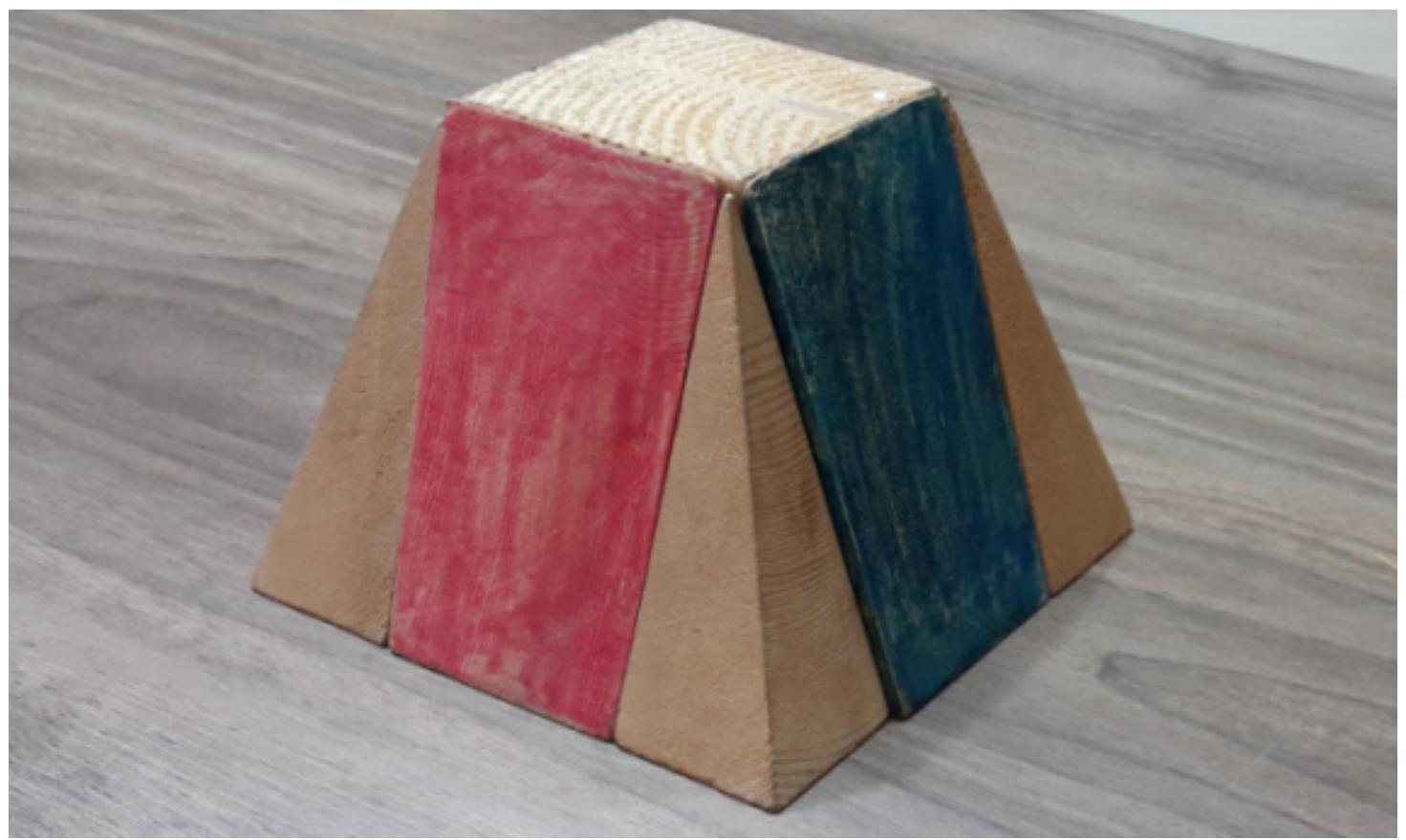

Figure 3. Model of the Completed Frustum Square Pyramid

The question "For this pyramid model, which shapes can you form by assembling bilateral parts?" was directed to the students in the worksheets to make them think and reason. Students tried to assemble bilateral parts and think over possible shapes to be formed in this stage of the study. This stage resembled a jigsaw puzzle. For this reason, it was a significant stage that enables students to improve their psychomotor skills. The teacher visited each group and controlled the resulting geometric shapes and the challenges, and helped the groups that were having difficulties. The question "What is the relationship between the volume of the frustum pyramid in the first stage and the volume of new geometric shapes formed with the parts of frustum pyramid?" was addressed to the students regarding the results of the assembling process. The aim was to help students interact with the information and link their prior and new knowledge. This was a significant stage contributing to the learning process.

\section{Written Feedback Forms}


The written feedback form was designed by the researcher in order to obtain student views about the activities. The feedback form included 4 open-ended questions. The first question was "Have you ever been involved in such a study?". In the second question it was asked whether the activity was interesting and what they thought about the activities. The third question was about the challenges, and the fourth was about whether they would like to practice similar activities in classes. After completing the activities, these written feedback forms were handed out and students were asked to answer the questions on the form. Data obtained through the forms were analyzed and coded. The coding process was conducted by the researcher and an expert academic in the field. For reliability measurements, the model suggested by Miles and Huberman [32] (1994) ("Reliability $=$ Agreement/ (Agreement + Disagreement) was used. A reliability score over $70 \%$ showed that the study was reliable.

\section{Observations and Informal Interviews}

Observations are undertaken to analyze spontaneous or consciously prepared events in a systematic and purposeful way. Observations may be natural or systematic. In natural observation, the events are observed in their natural environments without intervention from outside. In action research, the observation is conducted by the participant researcher teacher. The reactions of students are observed under natural conditions and critical incidents are recorded. During the present study, the researcher teacher observed the students and tried to determine their reactions towards activities and challenges. Moreover, within the implementation process, the researcher observed the practices of students, undertook informal interviews with them, and collected information about the activities. The informal interviews were held with the representatives of each group. The interviews were recorded with a tape recorder.

\section{Analysis of Data}

The information obtained through feedback forms which included students' remarks was analyzed qualitatively. Content analysis was undertaken in order to obtain qualitative data related to the activities from history of mathematics. Yıldırım and Şimşek [33] state that resembling data obtained through content analysis is grouped into specific concepts and themes, and corrections are made in order to ease the understanding of readers. The data obtained through content analysis was analyzed in 4 stages: Coding data, determination of themes, arrangement of the codes and themes, definition and interpretation of the findings [33]. Moreover, samples of student answers to each question in the feedback form were selected. Coding was completed by the researcher and an expert academic in the field. For reliability measurements, the model suggested by Miles and Huberman [32] (1994) ("Reliability = Agreement/ (Agreement + Disagreement) was used. The consistency level of coding was measured as 0.94 . The interviews recorded by a tape recorder were transcribed and given to students for their approval.

\section{The Role of the Researcher}

The researcher worked as a mathematics teacher between the years 2002 and 2014. He completed his MA and PhD Studies in the field of elementary mathematics education. He took the course "Historical Development of Mathematical Concepts" during his PhD. Thanks to this course, he gained experience about why and how history of mathematics is used within instructional environments. As a result, he decided to enrich his classes with the history of mathematics and determine student improvement resulting from these activities. The researcher conducted participative observations and informal interviews during the activities, and recorded student reactions from beginning to end. He did not add his own feelings and ideas to the analysis process.

\section{Findings}

\section{Findings Obtained through Observations and Informal Interviews}

Wood models were handed out to each group together with worksheets in order to form frustum pyramids and find their volumes. Students were asked to assemble the bilateral parts of the models forming frustum pyramids and identify the new shape obtained. Some groups had difficulty in assembling these at the beginning. Students S7 and S16 had difficulty in assembling the parts properly and making calculations. Students S13 and S14 kept looking at each other and laughing during the activities and seemed to have other things in mind. This stage was completed at different times in each group, but some students had difficulty in writing the names of the geometric shapes they had created. Student S9 stated that as a result of assembling bilateral parts, squares, triangles and rectangles could be created. This shows that this student did not consider the geometric shapes as three-dimensional. This requires that all students should know rectangular, tetragonal prisms and square pyramid as well as their properties and be able to give examples of three-dimensional geometric shapes from their environment. In this way, the activity could be carried out more effectively. Students calculated volumes of geometric shapes they had obtained after assembling the wood models properly. The problems experienced by some of the students during the formation process were experienced in cubage attempts as well. There were also problems in determining the edges and conducting mathematical processes properly. The researcher teacher became a part of the activity at this point and showed the edges of geometric shapes on the models and asked lengths of the edges to students. Examples from students S10 and $\mathrm{S} 24$ are given below. 


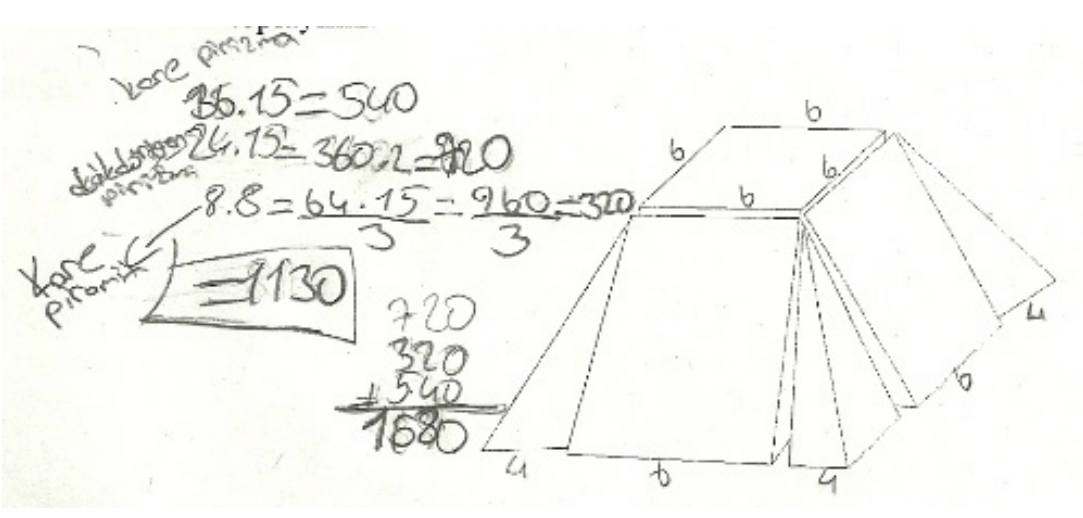

Practice of student S24

In addition to observations, the researcher held informal interviews with the students as well. These informal interviews were held with a representative from each group during the implementation process. An example from the informal interview with the representative of the first group, student S6, is given below:

Teacher: What did you think of the activity?

S6: Sir, it was very interesting. We formed new shapes with wooden pieces and found the volume of the frustum pyramid. This helps us remember easily.

Teacher: What were your classes like before?

S6: Before this, we mostly used our textbook. The teacher explained the topic and then we solved questions.

Teacher: Which style did you like better?

S6: The activities you prepared were better. Classes with activities are better.

Teacher: Why?

S6: Because we found the rules. We used wooden pieces.

As can be seen, student S6 mentioned the contribution of these activities to his cognitive learning and implied that deducing rules through concrete models can result in permanent learning. The student also stated that mathematics classes had previously been conducted using a teacher-centered approach and the new approach was better. During the interview with the representative of the second group, student S18 stated that they had never before encountered such teaching materials and they should be used during classes. Part of the interview with the representative of the second group, S18, is given below:

Teacher: Did you like the activity, S18?

S18: Yes, it was entertaining, like a puzzle. I wish we could learn all topics in this way.

Teacher: Then, what is your opinion about the material used? Have you ever done something like this in mathematics classes before?

S18: No, in previous years, teachers used to explain the subject, write questions on the board, solve them themselves first, and then ask us to solve them too. I now see mathematics can be different.

Teacher: How so?

S18: I mean interesting. Using different materials, tools, solutions...

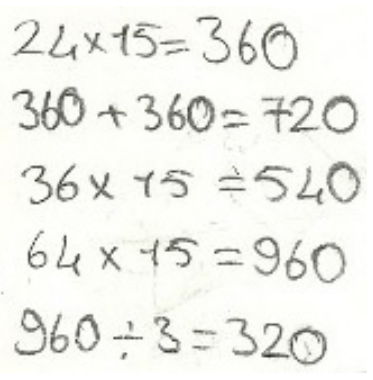

Practice of student S10

Teacher: You mention solutions. Which type of solution did you like best?

S18: It was good to assemble wooden pieces and calculate the volumes of the new shapes we obtained. It is because we see that ancient people found different results with a different idea.

Teacher: What result did you obtain through an analogy?

S18: The same result. But we always use paper and pencil in mathematics classes. It was interesting to reach the result by using frustum pyramid pieces.

Teacher: What do you think about the people who used this method in ancient times?

S18: It is amazing to see that they found the volumes of frustum pyramids in such a way when there was no technology.

Student S18 stated that the activity was entertaining and contributed to their cognitive learning process. He also expressed that they had not used such activities in previous years and this kind of activity was an interesting experience for them. Moreover, it may be seen that student beliefs about the nature of mathematics became stronger. The student stated that there may be more than one solution in mathematics. During the informal interview with the representative of the third group, it was seen that student S10 had similar ideas to S6 and S18, but additionally expressed his admiration for ancient people's intelligence and creativity.

Teacher: Did you like the activity?

S10: Yes sir, we assembled pieces and formed new geometric shapes, made calculations.

Teacher: What did you gain with this activity?

S10: I learned that we can use different tools and materials in mathematics and that ancient people also studied it.

Teacher: You said ancient people... What do you think about their work?

S10: I see they were intelligent and creative people. It was astonishing to see how advanced they were in mathematics in those times.

During the interview with the representative of the fourth group, student S2 stated that he used to believe mathematics 
had emerged 100 years ago, showing that historical content had not been part of the mathematics course in previous years.

Teacher: Did you like the activity?

S2: Yes, sir.

Teacher: So what did you like most?

S2: We studied in groups. We never did that before. And we tried to find rules by using tools and materials.

Teacher: You have never used tools and materials in your classes before?

S2: We have, but just a ruler and goniometer.

Teacher: So what did you learn with this activity?

S2: I learned that mathematics was present a long time ago, even in 3000 BC. People tried different methods to get results.

Teacher: What did you think before about the origin of mathematics?

S2: I thought mathematics emerged around 100 years ago.

Teacher: OK. What else did you think about our activity?

S2: We obtained the result by making an analogy and assembling the pieces.

Teacher: What was the result like?

S2: We got the same result. It was good to see another solution.

Similar results were obtained in other interviews, too. It was found that mathematics classes had been conducted in a teacher-centered way, students never encountered activities that enabled them to find the results by themselves, and historical contents had not been part of classes. The new activities were found to be instructive, interesting and entertaining. They changed students' beliefs about the nature of mathematics. The students learned that there were different solutions to problems and that mathematics emerged roughly 5000 years ago. Interviews were also held with students S9 and S17, who had particular difficulty in identifying and designating the shapes formed through assembling pieces and making calculations. Examples from these interviews are below:
Teacher: You had difficulty in the activity. What was the reason for this?

S9: Sir, I have problems with shapes. I think that was the reason.

Teacher: So you don't like geometry?

S9: I don't like, my teacher.

Teacher: (Pointing at the rectangular prism) can you tell the name of this shape?

S9: (Hesitating for a while) It is rectangle, my teacher. Isn't it?

From the interview made with student S9, it can be inferred that the student had difficulty in the activity because he did not know three-dimensional geometric shapes.

Teacher: I think you had difficulty with the activity. Can you tell me the reason?

S17: Actually I could assemble the pieces. But I have some problems with mathematical processes. And that posed a big challenge for me. Because of that I tried to look at my friends' work.

In conclusion, it was observed that students enjoyed forming frustum pyramids through assembling wooden pieces and calculating the volume of frustum pyramids by totalizing volumes of the pieces. The students were amazed that this method had been used around 3000 BC and they referred to the ancients as intelligent and creative. It was also observed that some students had difficulty with the activity due to lack of prior knowledge.

\section{Findings Obtained through Feedback Forms}

At the end of the activity, feedback forms were handed out to students and four questions were asked: "Did you take part in a similar activity in the previous year and would you like to do similar activities in the future?", "Did you enjoy the activity?", "What did you gain with this activity?", "What were the challenges you experienced during this activity?". Table 1 shows the findings obtained through the analysis of answers to the question "Did you take part in a similar activity in the previous year and would you like to do similar activities in the future?" are given in Table 1.

Table 1. Student responses to whether they took part in similar activities before and whether they would like to do them in the future

\begin{tabular}{ccc}
\hline Did you take part in a similar activity in previous years? & frequency & $\%$ \\
\hline Yes & 0 & 24 \\
\hline No & frequency & \\
\hline Would you like to do similar activities in the future? & 24 & \\
\hline Yes & 0 & \\
\hline No &
\end{tabular}

While using the activity in a state school, all of the students stated that they had never encountered such activities and would like to repeat them in the future. Answers to the question "Did you enjoy the activity?" are presented in Table 2.

Table 2. Student responses to whether they enjoyed the activity or not

\begin{tabular}{ccc}
\hline Did you enjoy the activities? & frequency & $\%$ \\
\hline Yes & 20 \\
\hline No & 4 \\
\hline
\end{tabular}


Table 2 shows that $83 \%$ of all students enjoyed the activities. Only 4 students (S7, S13, S14 and S16) expressed that they did not enjoy them. A similar situation was present in the observations made throughout the activity. The themes and student responses obtained in the analysis of the question about student gains are as follows:

Table 3. Student responses to gains obtained with the activities

\begin{tabular}{ccl}
\hline Themes & frequency & \multicolumn{1}{c}{ Supportive Expressions } \\
\hline Contribution to cognitive learning & 14 & $\begin{array}{l}\text { "We made dissection and assembly with wooden pieces and found the } \\
\text { sum ourselves, so we can remember what we learn easily." }\end{array}$ \\
\hline Contribution to affective learning & 20 & $\begin{array}{l}\text { "We assembled pieces like a jigsaw puzzle and found the result adding } \\
\text { volumes of all pieces. Mathematics is more entertaining in this way." }\end{array}$ \\
\hline Intelligent and creative people & 7 & $\begin{array}{l}\text { "People used such methods } 4000 \text { years ago, it shows that they were } \\
\text { very intelligent people." }\end{array}$ \\
\hline Use of different materials & 11 & $\begin{array}{l}\text { "I wish we could use different materials like this in our classes; it is } \\
\text { more enjoyable in this way." }\end{array}$ \\
\hline A deep rooted lesson & 18 & $\begin{array}{l}\text { "Mathematics existed a long time ago. I didn't know this. I thought it } \\
\text { was introduced later." }\end{array}$ \\
\hline Different solutions & 19 & $\begin{array}{l}\text { "We could find the volume of the frustum square pyramid. But we also } \\
\text { learned that we can reach this result in various ways." }\end{array}$ \\
\hline
\end{tabular}

Table 4. Student responses to the question about challenges they encountered during the activities

\begin{tabular}{ccc}
\hline Themes & frequency & Supportive Expressions \\
\hline I had difficulty & 5 & $\begin{array}{l}\text { "I had difficulty in assembling the pieces. Also in calculations. I'm already not good at } \\
\text { mathematical processes." }\end{array}$ \\
\hline I had some difficulty & 4 & $\begin{array}{l}\text { "I had difficulty in assembling pieces at the beginning, but my friends and I found the } \\
\text { correct sum together after a discussion." }\end{array}$ \\
\hline $\begin{array}{c}\text { I did not have any } \\
\text { difficulty }\end{array}$ & 15 & $\begin{array}{c}\text { "It was easy to assemble the pieces. After that we measured the lengths of geometric } \\
\text { shapes with a ruler and found the volumes. It was easy I think." }\end{array}$ \\
\hline
\end{tabular}

Most students thought that the activities contributed to their cognitive and affective learning. They expressed that mathematics dates back to old times and that the ancients had had reasonable and creative solutions. Most students understood that there is more than one solution in mathematics. This shows that they changed their beliefs about mathematics positively. Findings obtained through the analysis of answers to the question "What were the challenges you experienced during this activity?" are given in Table 4.

The students who had difficulty due to lack of prior knowledge and calculation skills also expressed this in written forms. According to the findings from observations, informal interviews and feedback forms, it may be said that the activity was appropriate to students' levels. It can also be said that observation and interview results are congruent. The findings obtained through the three data collection tools revealed that students S7, S9, S13, S14 and S16 had difficulty in the activities. Most students found the activities enjoyable and informative. Students learned that people were involved in mathematics even around $3000 \mathrm{BC}$ and used different methods.

\section{Results and Discussion}

Historical content is used in various ways in the mathematics curricula in many countries [34]. For instance, in Germany, $8^{\text {th }}$ grade textbooks teach consecutive positive whole numbers through exploration and include exercises on the magic squares of Ancient China and the multiplication practices of Ibn al-Bama beside modern multiplication methods [35]. The Gou Gu theorem, exploration of irrational numbers, Euclid, Lobachevsky and analogy axioms are some examples for the historical content used in Chinese mathematics textbooks [34]. In Turkey, life stories of erudite mathematicians, ancient numbers and symbols, pictures of these mathematicians and their work are included in secondary school mathematics textbooks [10]. However, this is believed to make students passive in the instructional process [3,9]. Compared to the textbooks in Turkey, those in Germany and China seem to give students a more participative role in the process through historical content [10]. Another point to take into account is the extent to which historical content is compatible with the objectives in the curriculum. This is particularly important for students who are preparing for centralized exams. Spending excessive time on historical content dissociated from the objectives will create indifference towards the use of history of mathematics and lead to the conclusion that such content is unnecessary [18]. The failure to draw a link between historical content and modern mathematics and objectives leads to difficulty and boredom on the students' part [19,20]. Another challenge in using history of mathematics is that students do not see such content as real mathematics and become confused by it $[7,13,15]$.

The findings of this study revealed that students had never 
encountered historical content in previous years, meaning that history of mathematics had not been included in classes by teachers. The reasons for this may be teacher beliefs in absolutism and their lack of knowledge and experience in using history of mathematics. Goodwin [36] (2007) compared the image of mathematics in teachers' minds and their knowledge levels in HoM. Teachers who received high scores in HoM knowledge test mentioned the socio-cultural and developing structure of mathematics. They stated that mathematics is not only rules and formulas. On the other hand, teachers who received low scores in HoM knowledge test seemed to believe that mathematics is a body of rules and formulas that are incompatible with each other [36]. Yet another reason for not using HoM in classes may be time restrictions due to a loaded curriculum.

The historical content used in this study was found instructive and entertaining by the students. These findings obtained in the study, however, are not compatible with the findings of previous studies conducted by Dickey [19] (2001), Tözluyurt [20] (2008), Kaye [21] (2008), Özdemir and Y1ldiz [22] (2015). Historical content used in the studies of Dickey [19] (2001) and Tözluyurt [20] (2008) were regarded as difficult and boring by the students. Students stated that they only liked the Treviso multiplication activity. Similarly, they had difficulty in writing Babylon numbers in the studies conducted by Kaye [21] (2008), Özdemir and Yild1z [22] (2015). These differences may be attributed to compatibility of historical content with the objectives in mathematics curricula. The historical content used in the present study was compatible with the course objectives. Students were allowed to dissect and assemble pieces using concrete models, find the volume and the rules of frustum square pyramids. They normally achieve more $[16,17]$ and enjoy the practices $[38,40]$ when they work actively with historical content compatible with modern mathematics and learn by creating their own products.

Another result revealed by the study was that students learned that mathematics is a deep-rooted lesson and there may be different solutions. They realized that mathematics originated around $3000 \mathrm{BC}$ and has a 5000-year history. The findings may be taken to imply that students developed positive attitudes towards the nature of mathematics. These results are compatible with the ones obtained by Krussel [39] (2000), Marshall [40] (2000), Liu and Niess [41] (2006) and Liu [42] (2009).

Although there are various ways of using history of mathematics, studies conducted in Turkey have mostly used historical snippets as historical content. In $6^{\text {th }}, 7^{\text {th }}$ and $8^{\text {th }}$ grade textbooks in Turkey, historical content includes life stories given at the beginning of new topics, pictures of mathematicians, ancient numbers, etc. Although such use of history of mathematics may be interesting, overuse could lead to the conclusion that historical content is irrelevant to modern mathematics and boring. Moreover, such use of historical content restrains students from being active participants in the learning process and building their own knowledge. This study showed how history of mathematics could be used as a teaching aid. The study may also enlighten teachers, teacher candidates and curriculum writers in how to use history of mathematics as a teaching aid and how to integrate it into textbooks.

History of mathematics has a potentially rich content. Teachers should view this rich content as a feasible teaching aid and be trained in using it. With such training, teachers in Turkey may be able to analyze the various effects of using history of mathematics (mistakes, historical problems, primary sources, etc.). However, at the outset, they should be well informed about the obstacles against the use of history of mathematics, the ways in which historical content may be used and relevant strategies.

\section{Suphi's Reflections and Professional Growth}

I included historical content in my lessons in previous years. My students converted Ancient Egyptian numbers into modern ones and vice versa. However, my students found this activity boring and thought it was a waste of time. They thought so as they knew that this kind of content would not be included in the upcoming centralized exams. For this reason, I decided to integrate new activities into my classes that are compatible with modern mathematics and the objectives stated in the mathematics curriculum and through which my students would construct their own knowledge. I found thanks to this experience that historical content may be interesting if compatible with the objectives. My students had never encountered such activities in previous years. They were not aware of the history of mathematics or different proof methods. With this study, they learned that mathematics dates back to old times and there are different mathematical methods available. The activities were instructive and entertaining for my students. I do not think that they will ever forget the volume rules of frustum pyramids as they figured these rules out by themselves. As a teacher, the activities enabled me to have a positive attitude towards the use of history of mathematics and use it more efficiently in my classes. 


\section{Appendix}

\section{Worksheet 1}
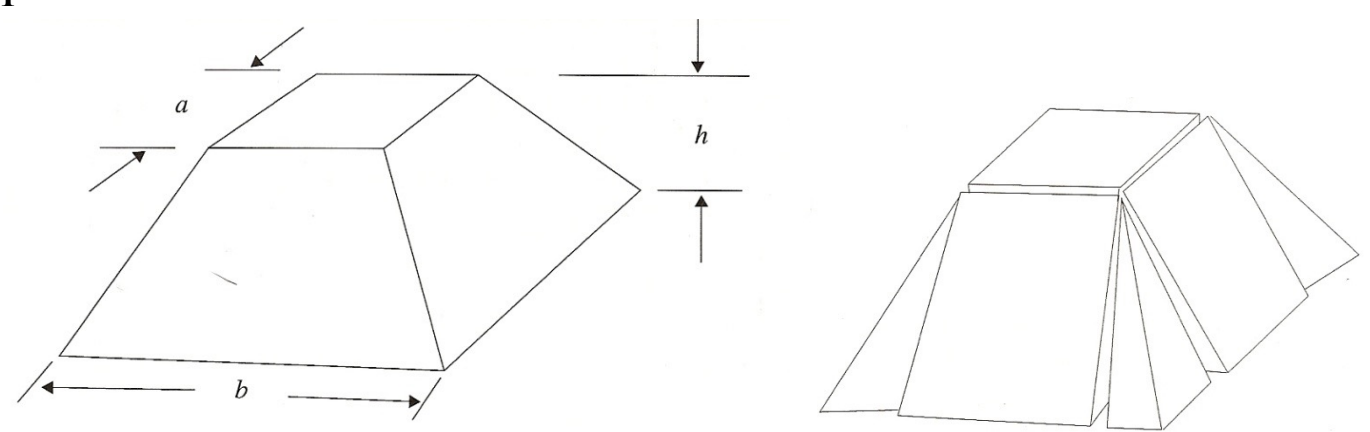

\section{Motivation}

What would you think if someone told you that a mathematical rule existed around $3000 \mathrm{BC}$ with a solution different from the one we use today? Would you think that this was possible 5000 years ago? Ask these questions to yourselves once again after doing the exercises below.

\section{Implementation Process}

Work in groups with the frustum square pyramid given to you and follow the instructions below.

- Assemble bilateral parts of the frustum square pyramid. Which shape did you obtain as a result?

- Assemble the four pieces on the edges of frustum square pyramid. Which shape did you obtain as a result?

- After assembling these pieces, write down the name of the geometric shape that results.

- Calculate volumes of all shapes by measuring their edges.

- What should you do in order to find the volume of the original frustum square pyramid?

- Write down the results mathematically.

- What does the result imply?

- Find the volume of the frustum square pyramid using analogy and compare the results you obtain. Which solution do you prefer?

\section{Assessment}

After the implementation, the action researcher (Suphi) told the students that the dissection method was used in $3000 \mathrm{BC}$ by Ancient Egyptians. Afterwards, students answered the questions below.

Summarize the work you did during the implementation process.

- Explain the gains you obtained with this activity.

There is question taken from Ancient Egyptian sources below. Answer the question.

\section{Moscow Papyrus Problem 14}

The lengths of the lower base, upper base and the height of a frustum square pyramid are $4 \mathrm{~cm}, 2 \mathrm{~cm}$ and $6 \mathrm{~cm}$, respectively. Please calculate the volume of this frustum pyramid.

\section{Modern Solution and the Solution with the Dissection Method}

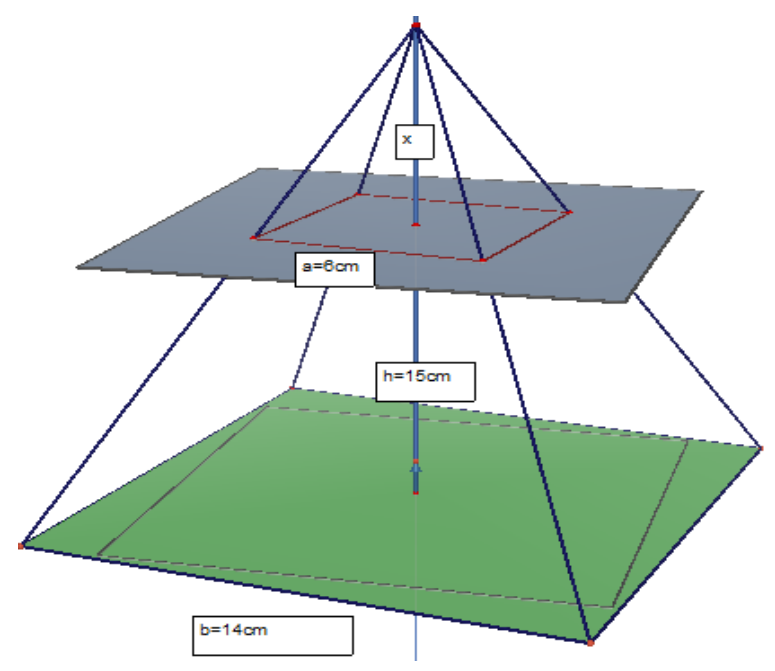

Modern-Solution

$\frac{6}{14}=\frac{x}{x+15}=k$

$7 x=3 x+45$

$4 x=45$

$x=\frac{45}{4}$

$\frac{V(\text { smallprism })}{V(\text { bigprism })}=k^{3}$

$\frac{135}{?}=\frac{27}{343}$

$V($ bigprism $)=1715$

$V($ frustumpyramid $)=1580$ 
Solution with the Dissection Method

$$
\begin{aligned}
& V_{1}=a^{2} x h=36 \times 15=540 \\
& V_{2}=a x \frac{b-a}{2} x h=6 x 4 \times 15=360 \times 2=720 \\
& V_{3}=(b-a)^{2} x h / 3=64 \times 15 / 3=64 \times 5=320 \\
& V_{4}=540+720+320=1580
\end{aligned}
$$

$* \mathrm{~V}_{1}$ : volume of square prism, $\mathrm{V}_{2}$ : volume of rectangular prism,

${ }^{*} \mathrm{~V}_{3}$ : volume of square pyramid, $\mathrm{V}_{4}$ : volume of frustum pyramid

$$
\begin{gathered}
V=a^{2} h+2 x\left(\frac{a b-a^{2}}{2}\right) x h+\left(\frac{b^{2}-2 a b+a^{2}}{3}\right) x h= \\
=a^{2} h+a b h-a^{2} h+\frac{b^{2} h}{3}-\frac{2 a b h}{3}+\frac{a^{2} h}{3} \\
V=\frac{h}{3}\left(a^{2}+a b+b^{2}\right)
\end{gathered}
$$

\section{REFERENCES}

[1] Ernest, P. (1998). The history of mathematics in the classroom. Mathematics in School, 27(4). 25-31.

[2] Fauvel, J. (1991). Using history in mathematics education. For the Learning of Mathematics, 11(2), 3-6.

[3] Fried, N. M. (2001). Can mathematics education and history of mathematics coexist?. Scince and Education, 10, 391-408.

[4] Gulikers, I., \& Blom, K. (2001). A historical angle, a survey of recent literature on the use and value of history in geometrical education. Educational Studies in Mathematics, 47, 223-258.

[5] Jankvist, T. U. (2009). A categorization of the whys and hows of using history in mathematics education. Educational Studies in Mathematics Education, 71(3), 235-261.

[6] Liu, P. (2003). Do teachers' need to incorporate the history of mathematics in their teaching?. Mathematics Teacher, 96(6), 416-421.

[7] Tzanakis, C., \& Arcavi, A. (2002). Integrating history of mathematics in the classroom: an analytic survey, In Favuel, J. and Van Manen, J. (Eds.), History in mathematics education (pp. 201-240), Netherlands: Kluwer Academic Publishers.

[8] Clark, K. M. (2012). History of mathematics: Illuminating understanding of school mathematics concepts for prospective mathematics teachers. Educational Studies in Mathematics, 81(1), 67-84. doi: 10.1007/s10649-011-9361-y

[9] Swetz, J. W. (1997). Using problems from the history of mathematics in classroom instruction, In Swetz, F., Fauval, J., Bekken, O., Johansson, B. and Katz, V. (Eds.) Learn from the masters. The Mathematical Association of America.

[10] Baki, A., \& Bütüner, S. Ö. (2013). The ways of using the history of mathematics in 6th, 7th and 8th grade mathematics textbooks. Elementary Education Online, 12(3), 849-872.

[11] Nooney, K. (2002). A Critical question: why can't mathematics education and history of mathematics coexist?, Article Review. The Mathematics Educator, 12(1), 1-5.

[12] Barnett, J. H., Lodder, J., \& Pengelley, D. (2014). The pedagogy of primary historical sources in mathematics: classroom practice meets theoretical frameworks. Science \& Education, 23, 7-27.

[13] Siu, M. K. (2007). No, I don't use history of mathematics in my class. why? In F. Furinghetti, S. Kaijser, and C. Tzanakis (Eds.), Proceedings HPM2004 \& ESU4 (revised edition, pp. 268-277). Uppsala: Uppsala Universitet.

[14] Ho, W. K. (2008). Using history of mathematics in the teaching and learning of mathematics in Singapore. Paper presented at the 1st RICE, Singapore: Raffles Junior College.

[15] Panasuk, R. M., \& Horton, L. B. (2012). Integrating history of mathematics into curriculum: what are the chances and constraints?. International Electronic Journal of Mathematics Education, 7(1), 3-20.

[16] Glaubitz, M. R. (2007, July). The use of original sources in the classroom. Proceedings of the 5th European Summer University, Prague.

[17] Nataraj, M. S., \& Thomas, M. O. J. (2009). Developing understanding of number system structure from the history of mathematics. Mathematics Education Research Journal, 21(2), 96-115.

[18] Bütüner, S. Ö. (2015). Reflections from classroom environments enriched with the mathematics historical activities: an action research. Unpublished doctoral dissertation. Karadeniz Technical University, Trabzon, Turkey.

[19] Dickey, G. (2001). A historical approach to teaching the british columbia mathematics eight course. Unpublished master dissertation, Simon Fraser University.

[20] Tözluyurt, E. (2008). The perceptions of senior high students regarding the lessons, in which activities chosen from history of mathematics are used on the subjects of numbers learning area. Unpublished master dissertation, Gazi University, Ankara, Turkey.

[21] Kaye, E. (2008). The aims of and responses to a history of mathematics videoconferencing project for schools, $\begin{array}{llll}\text { Retrieved } \quad \text { May } & 5, & 2008 \text { from }\end{array}$ http://bsrlm.org.uk/IPs/ip28-3/BSRLM-IP-28-3-12.pdf.

[22] Özdemir, A. Ș., Y1ldı, S. G. (2015). Using History of Mathematics in the Classroom: Babylonian Number System. Amasya Education Journal, 4(1), 26-49.

[23] Komisyon (2011). Mathematics 6 student textbook. Ankara: Ministary of Education Publications.

[24] Aygün Ç. S., Aynur, N., Çuha, S. S., Karaman, U., Özçelik, U., Ulubay, M. \& Ünsal. N. (2011b). Mathematics 7 student textbook. Ankara: Ministary of Education Publications.

[25] Aygün Ç. S., Aynur, N., Çoşkuntürk, N., Çuha, S. S., Karaman, U., Özçelik, U., Ulubay, M. \& Ünsal. N. (2011a). Mathematics 8 student textbook. Ankara: Ministary of Education Publications. 
[26] Turkish ministry of education (2013). Middle school mathematics teaching program http://ttkb.meb.gov.tr/www/guncellenen-ogretim-programlar $\mathrm{i} /$ icerik/151

[27] Van De Walle, J. A., Karp, K. S., Bay-Williams, J. M. (2013). Elementary and middle school mathematics: teaching developmentally, (7th ed.), Toronto: Pearson Allyn and Bacon.

[28] Swetz, F. J. (1994). Learning activities from the history of mathematics. Portland: Walch Publishing.

[29] McNiff, J., Lomax, P. and Whitehead, J. (1996). You and your action research project. London, GBR: RoutledgeFalmer.

[30] Johnson, A. (2005). A short guide to action research. İkinci Basım. USA: Pearson Education, Inc.

[31] Mertler, C. A. (2006). Action research: teachers as researchers in the classroom. London, Sage Publications.

[32] Miles, M.B. \& Huberman, A.M. (1994). Qualitative data analysis: An expanded sourcebook. (Second Edition). California: SAGE Publications.

[33] Yıldırım, A. \& Şimşek, H. (2013). Quantitative research metjods in social sciences (9th edition). Ankara: Seckin Publishing.

[34] Fasanelli, F. (2000). The political context, İçinde, (Ed: Favuel, J. and Van Manen, J.). History in mathematics education, (pp.201-240), Netherlands: Kluwer Academic Publishers.

[35] Schmid, A., \& Weidig, I. (2003). Lambacher-Schweizer, Ausgabe Sachsen: 6. Schuljahr, Lösungsheft.
[36] Goodwin, D. M. (2007). Exploring the relationship between high school teachers' mathematics history knowledge and their images of mathematics. Unpublished doctoral dissertation, University of Massachusetts Lowell.

[37] Baki, A., \& Güven, B. (2009). Khayyam with Cabri: experiences of pre-service mathematics teachers with Khayyam's solution of cubic equations in dynamic geometry environment. Teaching mathematics and Its Applications, 28, $1-9$.

[38] Haverhals, N., \& Roscoe, M. (2010). The history of mathematics as a pedagogical tool: teaching the integral of the secant via Mercator's projection. The Montana Mathematics Enthusiast, 7(2-3), 339-360.

[39] Krussel, L. (2000). Using history to further the understanding of mathematical concepts. Primus, 10(3), 273-276.

[40] Marshall, G. L. (2000). Using history of mathematics to improve secondary students' attitudes toward mathematics. Unpublished doctoral dissertation, Illinois State University.

[41] Liu, P., \& Niess, M. L. (2006). An exploratory study of college students' views of mathematical thinking in a historical approach calculus course. Mathematical Thinking and Learning, 8(4), 373-406.

[42] Liu, P. H. (2009). History as a platform for developing college students' epistemological beliefs on mathematics. International Journal of Science and Mathematics Education, 7(3), 473-499. 